\title{
RP-HPLC Analytical Method Development and Validation for Simultaneous Estimation of Three Drugs: Glimepiride, Pioglitazone, and Metformin and Its Pharmaceutical Dosage Forms
}

\author{
Gadapa Nirupa, ${ }^{1}$ and Upendra M. Tripathi ${ }^{2}$ \\ ${ }^{1}$ Department of Chemistry, Jawaharlal Nehru Technological University, Kukatpally, Hyderabad 500085, AP, India \\ ${ }^{2}$ Startech Labs Pvt. Ltd., 2nd Floor, SMR Chambers, H. Number: 1-58/7 Madinaguda, Hyderabad 500050, AP, India
}

Correspondence should be addressed to Upendra M. Tripathi; drtripathi@startechlabs.com

Received 11 February 2012; Accepted 2 May 2012

Academic Editor: Jun Zhang

Copyright (C) 2013 G. Nirupa and U. M. Tripathi. This is an open access article distributed under the Creative Commons Attribution License, which permits unrestricted use, distribution, and reproduction in any medium, provided the original work is properly cited.

Developing a single analytical method for estimation of individual drug from a multidrug composition is a very challenging task. A simple, rapid, precise, and reliable reverse phase HPLC method was developed for the separation and estimation of three drugs glimepiride, pioglitazone and metformin in bulk drug mix and pharmaceutical dosage forms. The estimation was carried out using Inertsil ODS-3V $(250 \mathrm{~mm} \times 4.6 \mathrm{~mm}, 5 \mu \mathrm{m})$ column; mobile phase consisting of acetonitrile, tetrahydrofuran, and buffer at pH 5; the flow rate of $1.7 \mathrm{~mL} / \mathrm{min}$ and ultraviolet detection at $228 \mathrm{~nm}$. All the three drugs were properly resolved having run time of 5 minutes, 3.9 minutes and 1.3 minutes for glimepiride, pioglitazone, and metformin, respectively. The method was validated as a final verification of method development with respect to precision, linearity, accuracy, ruggedness, and robustness. The validated method was successfully applied to the commercially available pharmaceutical dosage form, yielding very good and reproducible result.

\section{Introduction}

In the current Indian scenario, most commonly attacking disease to a common man has been found to be diabetes. Recent studies indicate that prevalence of type- 2 diabetes is rapidly increasing in the society. Type- 2 diabetes is a progressive disorder with a consistent and steady increase in glycosylated hemoglobin $\left(\mathrm{HbA}_{1} \mathrm{C}\right)$ overtime associated with enhanced risk of micro- and macrovascular complications and a substantial reduction in life expectancy. There are three major pathophysiologic abnormalities associated with type- 2 diabetes: (i) impaired insulin secretion, (ii) excessive hepatic glucose output, and (iii) insulin resistance in skeletal muscles, liver and adipose tissue. These defects have been treated by use of oral insulin secretagogues (sulphonyl ureas/glinides) or insulin, biguanides, and thiazolidinediones, respectively [1].
Glimepiride is a medium-to-long acting sulphonyl urea antidiabetic drug. It is chemically 1-[[p-[2-(3-Ethyl-4methyl-2-oxo-3-pyrroline-1 carboxamido)ethyl]phenyl]sulfonyl]-3-(trans-4-methyl cyclohexyl) urea. The primary mechanism of action of glimepiride in lowering blood glucose appears to be dependent on stimulating the release of insulin from functioning pancreatic beta cells. Metformin hydrochloride is also antidiabetic drug in the biguanide class and it is chemically 1,1-dimethyl biguanide monohydrochloride. It decreases hepatic glucose production, decreases intestinal absorption of glucose, and improves insulin sensitivity by increasing peripheral glucose uptake and utilization. Pioglitazone is a prescription drug of thiazolidinedione class with hypoglycemic (antihyperglycemic, antidiabetic) action; it is chemically $( \pm$ ) 5-[[4-[2-(5-Ethyl2-pyridinyl)ethoxy]phenyl]methyl]-2,4] thiazolidinedione monohydrochloride. It selectively stimulates the nuclear 
<smiles>CCC1=C(C)CN(C(=O)NCCc2ccc(S(=O)(=O)NC(=O)NC3CCC(C)CC3)cc2)C1=O</smiles>

(a)

(b)<smiles>CCc1ccc(CCOc2ccc(CC3SC(=O)NC3=O)cc2)nc1</smiles>

\section{Pioglitazone}

(c)

FIgure 1: Chemical structures of the drugs.

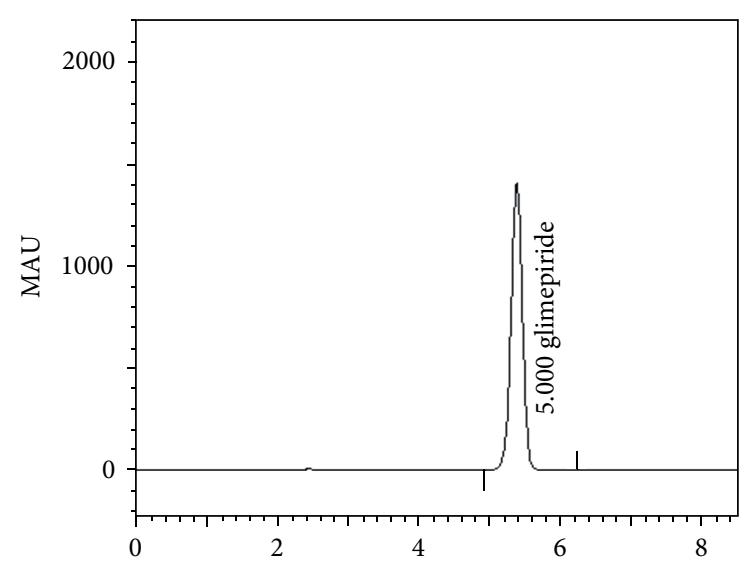

(a)

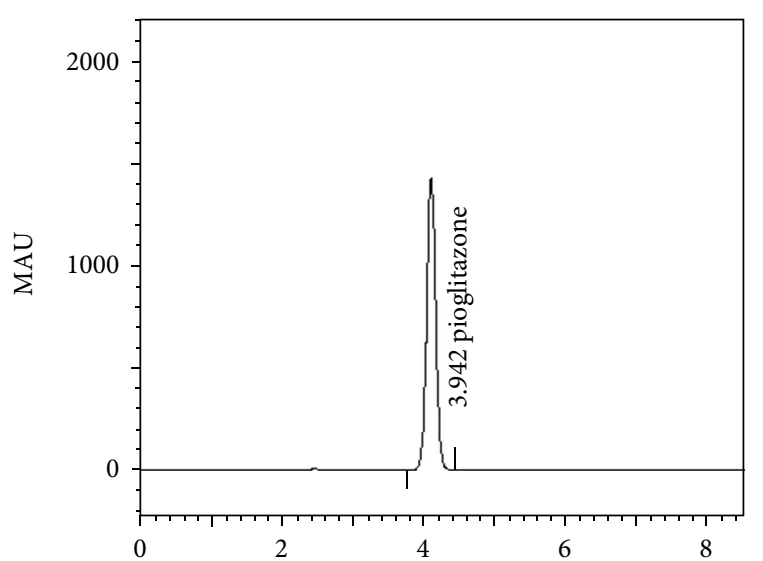

(b)

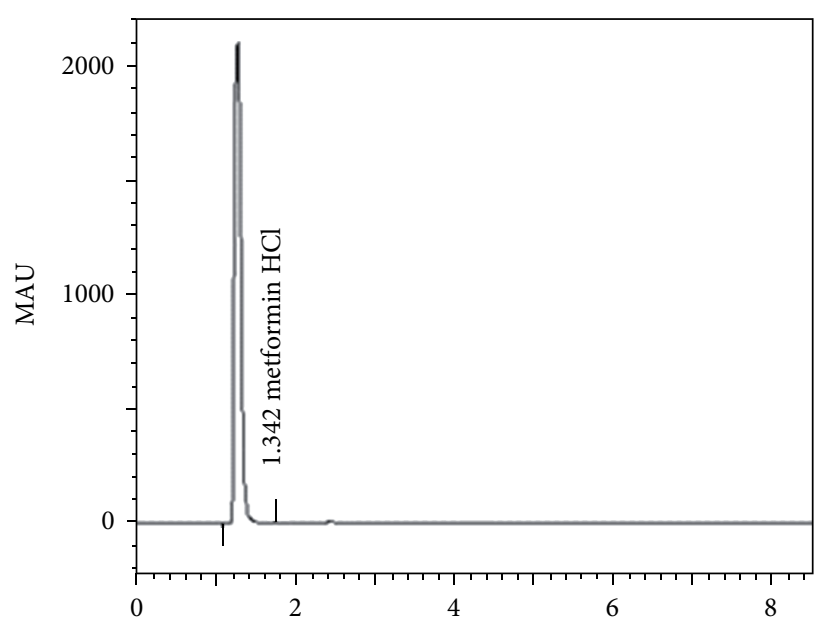

(c)

FIgURE 2: Individual drugs. 


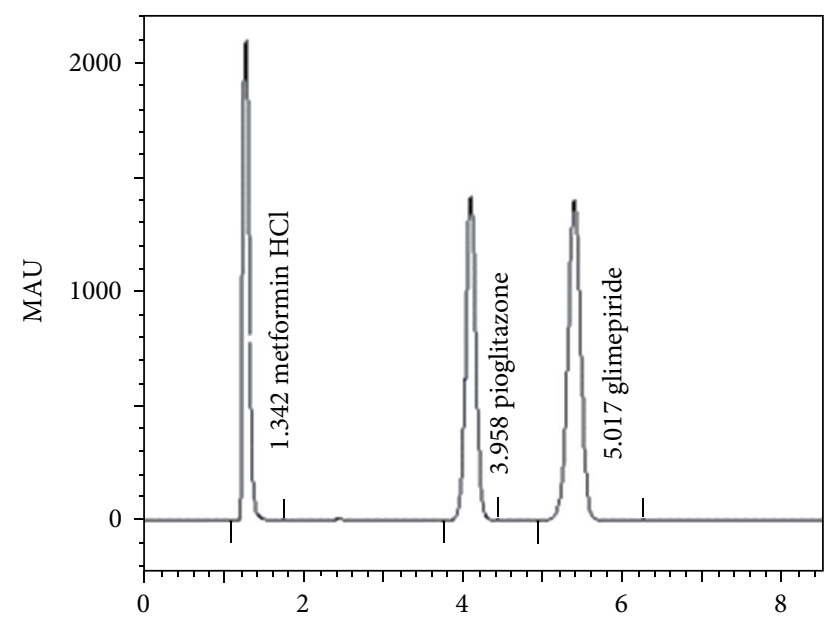

Figure 3: Drug mixture.

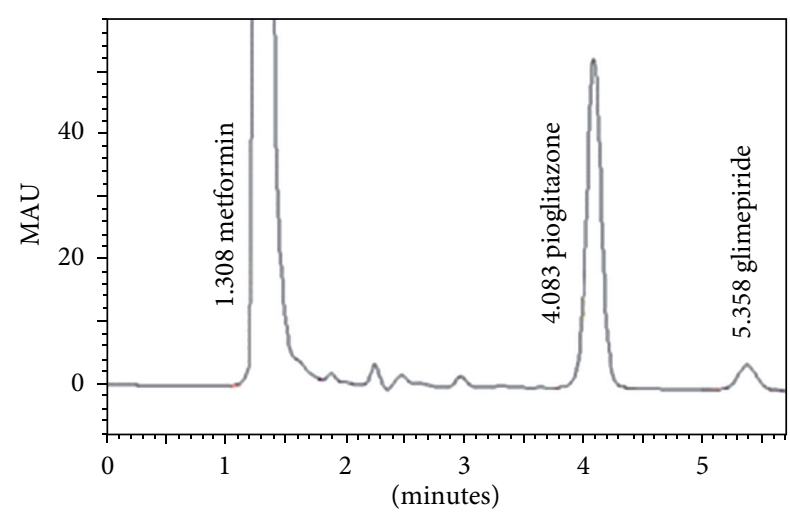

FIgURE 4: Dosage forms.

receptor peroxisome proliferator activated receptor-gamma $($ PPAR- $\gamma)$ and to a lesser extent PPAR- $\alpha$. It modulates the transcription of the insulin-sensitive genes involved in the control of glucose and lipid metabolism in the muscle, adipose tissue and the liver. As a result, pioglitazone reduces insulin resistance in the liver and peripheral tissues, increases the expense of insulin dependent glucose, decreases withdrawal of glucose from the liver, and reduces quantity of glucose, insulin, and glycosylated hemoglobin in the bloodstream. The combination of glimepiride, pioglitazone, and metformin sustained release complements each other and provides better glycemic control in the management of Type2 Diabetes and probably in the prevention of its associated macrovascular and microvascular complications [2].

The chemical structures of the drugs are as shown in Figure 1. Keeping the medical importance in mind, a group of drugs used for treating/maintaining diabetes, namely, glimepiride, pioglitazone, and metformin has been selected for method development and validation. All the three drugs are antidiabetic drugs. These drugs are very potent and are normally prescribed either individually or in combinations as per the demand of the situation. These three drugs are also available in the market as a combination, dosage forms.
TABLE 1: System suitability results.

\begin{tabular}{|c|c|c|}
\hline Standard & Average & $\%$ RSD \\
\hline \multicolumn{3}{|l|}{ Glimepiride } \\
\hline Retention time & 5.043 & 0.26 \\
\hline Area & 14711933 & 0.13 \\
\hline Resolution & 4.924 & \\
\hline Theoretical plates & 7063 & \\
\hline Asymmetry & 0.898 & \\
\hline \multicolumn{3}{|l|}{ Pioglitazone } \\
\hline Retention time & 3.977 & 0.27 \\
\hline Area & 11302936 & 0.1 \\
\hline Resolution & 15.52 & \\
\hline Theoretical plates & 6782 & \\
\hline Asymmetry & 0.94 & \\
\hline \multicolumn{3}{|l|}{ Metformin } \\
\hline Retention time & 1.342 & 0 \\
\hline Area & 11142195 & 0.31 \\
\hline Resolution & 0 & \\
\hline Theoretical plates & 1347 & \\
\hline Asymmetry & 1.17 & \\
\hline \multicolumn{3}{|l|}{ Dosage form } \\
\hline \multicolumn{3}{|l|}{ Glimepiride } \\
\hline Retention time & 5.071 & 0.11 \\
\hline Area & 14719434 & 0.1 \\
\hline Resolution & 4.99 & \\
\hline Theoretical plates & 7142.925 & \\
\hline Asymmetry & 0.88 & \\
\hline \multicolumn{3}{|l|}{ Pioglitazone } \\
\hline Retention time & 3.992 & 0 \\
\hline Area & 11285309.5 & 0.11 \\
\hline Resolution & 15.775 & \\
\hline Theoretical plates & 6893.845 & \\
\hline Asymmetry & 0.93 & \\
\hline \multicolumn{3}{|l|}{ Metformin } \\
\hline Retention time & 1.342 & 0 \\
\hline Area & 11109070.5 & 0.31 \\
\hline Resolution & 0 & \\
\hline Theoretical plates & 1396.245 & \\
\hline Asymmetry & 1.205 & \\
\hline
\end{tabular}

For individual estimation of each drug, several methods are available in the literature [3-7] even there are couple of methods available for estimation of two drugs at a time [814]. There are some methods where even more than 2 drugs are estimated at a time [15-18]. Very limited work has been done [19] for the simultaneous estimation of all the three drugs, namely, glimepiride, pioglitazone, and metformin.

For contributing such a novel cause, through this article, we have tried our best to develop a fast and user-friendly methodology for the simultaneous estimation of glimepiride, pioglitazone, and metformin, using reverse phase-HPLC method in bulk drug mix and pharmaceutical dosage forms. 


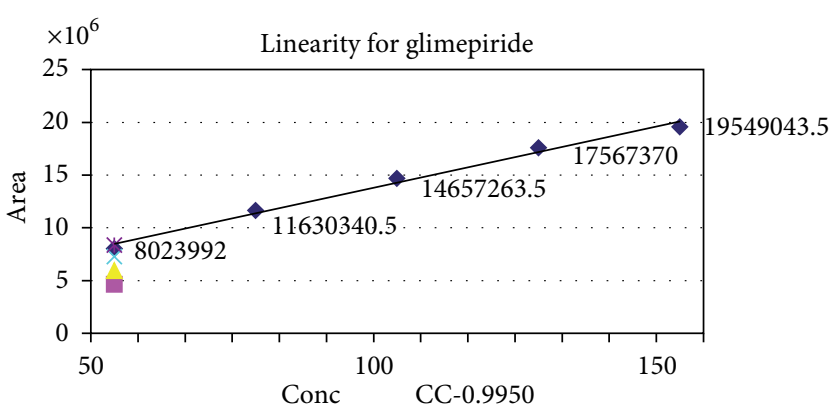

(a)

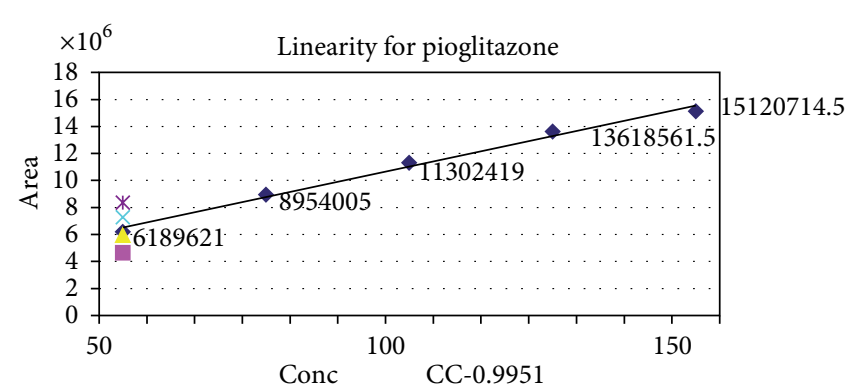

(b)

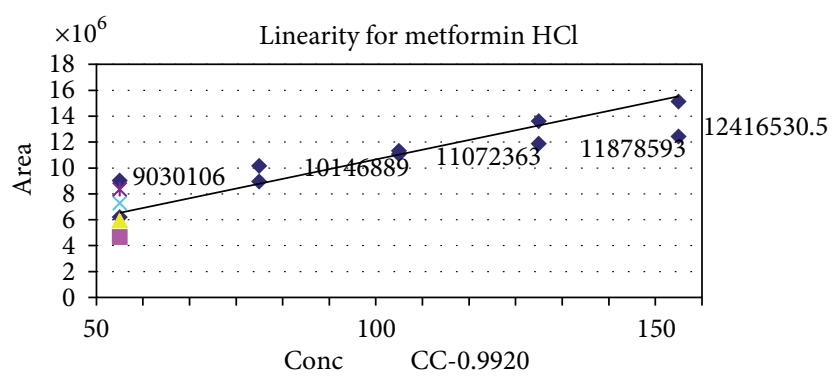

(c)

FIGURE 5: Graphs for linearity of the drugs.

TABLE 2: Linearity results.

\begin{tabular}{lcc}
\hline & Linearity range & Correlation coefficient \\
\hline Glimepiride & $50-150 \%$ & 0.995 \\
Pioglitazone & $50-150 \%$ & 0.9951 \\
Metformin & $50-150 \%$ & 0.992 \\
\hline
\end{tabular}

\section{Experimental Section}

In the present work, efforts have been made for the simultaneous estimation of glimepiride, pioglitazone, and metformin and its pharmaceutical dosage forms. Several trials have been made with respect to the mobile phase composition, columns, as well as UV detector's wavelength to develop a suitable and fast method for the analysis of all the three drugs, simultaneously. The ultimate method of analysis has been provided in Section 2 2.3.

2.1. Materials, Reagents, and Chemicals. Samples of glimepiride, pioglitazone, and metformin Hydrochloride Standards were obtained from Startech Labs. Combination drug tablets, Triblend 1, used for the experiment was manufactured by Akesis Pharma Pvt. Ltd. and Zoryl MP2 was manufactured by Intas Pharmaceuticals. HPLC-grade acetonitrile, tetrahydrofuran, dipotassium orthophosphate, trimethylamine, and orthophosphoric acid were obtained from Merck, Darmstadt, Germany.

2.2. Equipments. UV-Visible spectrophotometer used was Shimadzu, Model-2450. The HPLC instrument used was
Schimadzu make, model-LC-2010 CHT. Class VP Software was used for data acquisition.

2.3. Chromatographic Conditions. The Chromatographic column, Inertsil ODS-3 V $(250 \mathrm{~mm} \times 4.6 \mathrm{~mm}, 5 \mu \mathrm{m})$, column was used as a stationary phase. Mobile phase was prepared with buffer, acetonitrile, tetrahydrofuran (40:50:10). Buffer was prepared by dissolving $7.1 \mathrm{~g}$ of dipotassium hydrogen orthophosphate in $1000 \mathrm{~mL}$ of water. The $\mathrm{pH}$ was adjusted to 5.0 with orthophosphoric acid. Injection volume was $20 \mu \mathrm{L}$. The pump flow rate was $1.7 \mathrm{~mL} / \mathrm{min}$. The eluent was detected at $228 \mathrm{~nm}$ at $25^{\circ} \mathrm{C}$.

2.4. Preparation of Standard Solution. Standard solution of $0.4 \mathrm{mg} / \mathrm{mL}$ (treat this as $100 \%$ for various experimental purpose) was prepared by taking $10 \mathrm{mg}$ each of glimepiride, pioglitazone, and metformin Hydrochloride in $25 \mathrm{~mL}$ volumetric flask and $0.5 \mathrm{~mL}$ tetrahydrofuran was added and diluted upto the mark with mobile phase.

2.5. Preparation of Linearity Solutions. For linearity $150 \%$, $125 \%, 100 \%, 75 \%$, and $50 \%$ solutions were prepared. $150 \%$ solution was prepared by using $60 \mathrm{mg}$ each of glimepiride, pioglitazone, and metformin hydrochloride was dissolved in $100 \mathrm{~mL}$ for $150 \%$ solution. $20.83 \mathrm{~mL}$ of $150 \%$ solution was taken in a $25 \mathrm{~mL}$ volumetric flask and make up with mobile phase for $125 \%$ solution. $16.67 \mathrm{~mL}$ of $150 \%$ solution was taken in a $25 \mathrm{~mL}$ volumetric flask and make up with mobile phase for $100 \%$ solution. $12.5 \mathrm{~mL}$ of $150 \%$ solution was taken in a $25 \mathrm{~mL}$ volumetric flask and make up with mobile phase for $75 \%$ solution. $8.33 \mathrm{~mL}$ of $150 \%$ solution is taken in a $25 \mathrm{~mL}$ 
volumetric flask and make up with mobile phase for 50\% solution.

2.6. Sample Preparation for Accuracy. Five different solutions were prepared for performing the accuracy studies. The first solution was prepared by dissolving $10 \mathrm{mg}$ each of glimepiride, pioglitazone, and metformin in $25 \mathrm{~mL}$ volumetric flask and make up the solution with $50 \%$ linearity solution. The second solution was prepared by dissolving $10 \mathrm{mg}$ each of glimepiride, pioglitazone, and metformin in $25 \mathrm{~mL}$ volumetric flask and make up the solution with $75 \%$ linearity solution. The third solution was prepared by dissolving $10 \mathrm{mg}$ each of glimepiride, pioglitazone, and metformin in $25 \mathrm{~mL}$ volumetric flask and make up the solution with $100 \%$ linearity solution. The fourth solution was prepared by dissolving $10 \mathrm{mg}$ each of Glimepiride, pioglitazone, and metformin in $25 \mathrm{~mL}$ volumetric flask and make up the solution with $125 \%$ linearity solution. The fifth solution was prepared by dissolving $10 \mathrm{mg}$ each of glimepiride, pioglitazone, and metformin in $25 \mathrm{~mL}$ volumetric flask and make up the solution with $150 \%$ linearity solution.

2.7. Preparation of Sample Solution for Batch Analysis. Two commercial samples were used for batch analysis. Ten tablets were weighed and their average weight was calculated. The tablet was crushed to a homogeneous mixture and $20.19 \mathrm{mg}$ of Triblend 1 tablet and $23.23 \mathrm{mg}$ of Zoryl MP2 tablet have been dissolved in $25 \mathrm{~mL}$ each of the mobile phase. To extract the drug in solution, sonicate for 5 minutes followed by cyclomixing for 5 minutes. The resulting solution was filtered using Millipore syringe filter $(0.42 \mu)$. The resulting clear solution was injected in HPLC in duplicate as per the developed method.

\subsection{Analytical Method Validation}

2.8.1. Specificity of the Method. The terms selectivity and specificity are often used interchangeably. Specificity is the ability of the method to measure the analyte response in the presence of its potential impurities. This parameter was performed to know the retention time of each drug in a mixture and in the sample to understand if any drug-drug interaction or drug-excipient interaction is present.

2.8.2. System Suitability. System suitability test is used to verify that the resolution and reproducibility of the chromatographic systems are adequate for the analysis to be done. The tests are based on the fact that the equipment, electronics, samples to be analyzed constitute an integral system that can be evaluated as such. The limits for system suitability were set for theoretical plates, resolution, and asymmetry.

2.8.3. Linearity. Five concentrations of the standard mixture, $50 \%, 75 \%, 100 \%, 125 \%$, and $150 \%$, were injected and chromatogram was recorded. A graph was plotted for the concentration of the corresponding drug versus area. The correlation coefficient $(r)$ for each drug was calculated.
2.8.4. Accuracy. To determine the accuracy in sample preparation method of standard additions was made for measuring the recovery of the drugs. To the standard solution known concentrations of the drug $(50 \%, 75 \%, 100 \%, 125 \%$, and $150 \%)$ was added. Five different solutions were prepared as mentioned in Section 22.6. The accuracy was expressed as the percentage of the analytes recovery.

2.8.5. Method Precision. It is very important that the method developed should be precise. Six replicates of the sample prepared from the commercial tablets were injected and Assay was calculated to measure the repeatability of retention times and peak area of standard and sample.

2.8.6. Robustness. To verify the robustness of the method, the analysis was done under variable flow rates. The flow rate as per the developed method is $1.7 \mathrm{~mL} / \mathrm{min}$. This has been purposely changed to $1.5 \mathrm{~mL} / \mathrm{min}$ and $1.9 \mathrm{~mL} / \mathrm{min}$ and the chromatogram was obtained.

2.8.7. Ruggedness. To test the ruggedness of the method, the analysis was done on different days and different chemists to check for any changes in the chromatograph. The percentage RSD for the retention time and area was calculated.

2.8.8. Performance Test of the Method/Batch Analysis. The method is said to be reliable if it can be applied for the analysis of glimepiride, pioglitazone, and metformin simultaneously to the pharmaceutical dosage forms or commercial tablets. For this purpose, performance test of the method has been conducted on two market samples manufactured by Akesis Pharma Pvt. Ltd., brand name Triblend 1, and batch number TBD IP0310, and Zoryl MP2 manufactured by Intas Pharmaceuticals, Batch number TF 10D160.

\section{Results and Discussion}

After several permutation and combinations, above method has been optimized. It is evident from this method that this is a very fast method of analysis compared to the literature available [19]. We have been able to elute all the three drugs within $5 \mathrm{~min}$. In the current days, industries are looking for the methodology which can save sophisticated instruments and chemist's valuable time, and as a result they can release their product analysis report within lesser time. This is the reason why people are more attracted toward ultra-fast liquid chromatography (UFLC) $[20,21]$. In this regard, the current method developed by us is very fast and encouraging. The developed method was validated with a holistic approach according to ICH guidelines and details of findings are as below.

3.1. Specificity of the Method. The retention times of the standard drugs individually were measured and it was found to be $5.000 \mathrm{~min}, 3.942 \mathrm{~min}$, and $1.342 \mathrm{~min}$ for glimepiride, pioglitazone, and metformin respectively. The drugs were taken as mixture and injected for taking the chromatogram. All the three drugs (glimepiride, pioglitazone, and metformin 
TABLE 3: Results for accuracy of the method.

\begin{tabular}{|c|c|c|c|c|c|c|}
\hline & & Initial conc area & Sol 1 area & $50 \%$ area & Sol $1-50 \%$ area & $\%$ Recovery \\
\hline \multirow{4}{*}{ Sol 1} & Glimepiride & 14657264 & 22563825 & 8023992 & 14539833 & 99.2 \\
\hline & Pioglitazone & 11302419 & 17393625 & 6189621 & 11204004 & 99.13 \\
\hline & Metformin & 11072363 & 20056814 & 9030106 & 11026708 & 99.59 \\
\hline & & Initial conc area & Sol 2 area & $75 \%$ area & Sol $2-75 \%$ area & \% Recovery \\
\hline \multirow{4}{*}{ Sol 2} & Glimepiride & 14657264 & 26129857 & 11630341 & 14499516 & 98.92 \\
\hline & Pioglitazone & 11302419 & 20320163 & 8954005 & 11366158 & 100.56 \\
\hline & Metformin & 11072363 & 21365397 & 10146889 & 11218508 & 101.32 \\
\hline & & Initial conc area & Sol 3 area & $100 \%$ area & Sol $3-100 \%$ area & $\%$ Recovery \\
\hline \multirow{4}{*}{ Sol 3} & Glimepiride & 14657264 & 29367481 & 14657264 & 14710217 & 100.36 \\
\hline & Pioglitazone & 11302419 & 22539487 & 11302419 & 11237068 & 99.42 \\
\hline & Metformin & 11072363 & 22249678 & 11072363 & 11177315 & 100.95 \\
\hline & & Initial conc area & Sol 4 area & $125 \%$ area & Sol $4-125 \%$ area & $\%$ Recovery \\
\hline \multirow{4}{*}{ Sol 4} & Glimepiride & 14657264 & 32182741 & 17567370 & 14615371 & 99.71 \\
\hline & Pioglitazone & 11302419 & 28483584 & 13618562 & 11225022 & 99.32 \\
\hline & Metformin & 11072363 & 22950236 & 11878593 & 11071643 & 99.99 \\
\hline & & Initial conc area & Sol 5 area & $150 \%$ area & Sol 5-150\% & \% Recovery \\
\hline \multirow{3}{*}{ Sol 5} & Glimepiride & 14657264 & 34362870 & 19549044 & 14813826 & 101.07 \\
\hline & Pioglitazone & 11302419 & 26320185 & 15120715 & 11199470 & 99.09 \\
\hline & Metformin & 11072363 & 23472537 & 12416531 & 11056006 & 99.85 \\
\hline
\end{tabular}

TABLE 4: Method precision results.

\begin{tabular}{lllllllcc}
\hline & Assay 1 & Assay 2 & Assay 3 & Assay 4 & Assay 5 & Assay 6 & Average & $\%$ RSD \\
\hline Glimepiride & $99.55 \%$ & $99.05 \%$ & $99.21 \%$ & $99.15 \%$ & $99.21 \%$ & $99.72 \%$ & $99.31 \%$ & 0.21 \\
Pioglitazone & $99.37 \%$ & $99.44 \%$ & $99.31 \%$ & $99.54 \%$ & $99.41 \%$ & $99.26 \%$ & $99.38 \%$ & 0.099 \\
Metformin & $99.20 \%$ & $98.95 \%$ & $98.65 \%$ & $99.63 \%$ & $98.85 \%$ & $99.05 \%$ & $99.06 \%$ & 0.34 \\
\hline
\end{tabular}

hydrochloride) were resolved very nicely in a mixture. Retention time of all the three drugs in standard mix was found to be $5.017 \mathrm{~min}, 3.958 \mathrm{~min}$, and $1.342 \mathrm{~min}$ for glimepiride, pioglitazone, and metformin hydrochloride, respectively. This indicates there is no chromatographic interference between the analytes. The sample solution (pharmaceutical dosage form) was then injected and the chromatogram was obtained. The retention time of the drugs in the dosage form (tablet) was found to be $5.358 \mathrm{~min}, 4.083 \mathrm{~min}$, and $1.308 \mathrm{~min}$ for glimepiride, pioglitazone, and metformin hydrochloride, respectively. Respective HPLC chromatograms are represented in Figures 2, 3, and 4. There is no specific change in the chromatogram. This indicates that there is no drugexcipient interference and the drugs are properly resolved by this method. Therefore, this is a suitable method for the simultaneous estimation of glimepiride, pioglitazone, and metformin in drug mixture and dosage forms.

3.2. System Suitability. The suitability of the system was studied by performing the experiment and looking for changes in separation, retention times, and asymmetry of the peaks. Five injections of the standard and two injections of the sample were injected for this purpose. The resolution, areas, retention time, theoretical plates values and peak asymmetry were calculated for standard and sample solutions. Results obtained are given in Table 1.

3.3. Linearity. The correlation coefficient $(r)$ was calculated, and it was between 0.98 to 1.00 which is well within the acceptance criteria. The results are shown in Table 2. The concentration was found to be proportional to the area, and the response of the detector was determined to be linear over the range of 0.2 to $0.6 \mathrm{mg} / \mathrm{mL}$ as shown in the Figure 5 .

3.4. Accuracy. The percentage recovery of the results obtained is listed in Table 3 . The results indicate that the recoveries are well within the acceptance range, therefore, method is accurate and it can be used for the simultaneous estimation of glimepiride, pioglitazone, and metformin.

3.5. Method Precision. The percentage RSD values for the assays in precision study were calculated. The results as shown in Table 4 indicate that the method developed is precise.

3.6. Robustness. Due to deliberate change in the method, no changes were found in the chromatogram, the method developed is robust. The results are shown in Table 5. 
TABLE 5: \% RSD at different flow rates.

\begin{tabular}{lccc}
\hline & Retention times \% RSD & Areas \% RSD & Sample area \% RSD \\
\hline $1.5 \mathrm{~mL} /$ min & & & 0.4 \\
Glimepiride & 0.05 & 0.14 & 0.22 \\
Pioglitazone & 0.04 & 0.09 & 0.22 \\
Metformin & 0.06 & 0.52 & 0.14 \\
\hline $1.9 \mathrm{~mL} / \mathrm{min}$ & & & 0.01 \\
Glimepiride & 0.07 & 0.05 & 0.18 \\
Pioglitazone & 0.03 & 0.21 & \\
Metformin & 0 & & \\
\hline
\end{tabular}

TABLE 6: RSD of the drugs on different days and different analysts.

\begin{tabular}{cccc}
\hline \multicolumn{2}{c}{ Retention time \% RSD } & Areas \% RSD & Sample area \% RSD \\
\hline $\begin{array}{c}\text { Day 1-Analyst 1 } \\
\text { Glimepiride }\end{array}$ & 0.03 & 0.1 & 0.04 \\
Pioglitazone & 0.08 & 0.1 & 0.04 \\
Metformin & 0.03 & 0.01 & 0.02 \\
\hline Day 2-Analyst 2 & & & \\
Glimepiride & 0.04 & 0.04 & 0.05 \\
Pioglitazone & 0.06 & 0.01 & 0.03 \\
Metformin & 0.08 & 0.1 & 0.06 \\
\hline
\end{tabular}

TABLE 7: Estimation of the drugs in commercial samples.

\begin{tabular}{cccc}
\hline & Label claim & Acquired data & Assay\% \\
\hline Triblend 1 & & & \\
Glimepiride & $1 \mathrm{mg} / \mathrm{tab}$ & $1.01 \mathrm{mg} / \mathrm{tab}$ & $101 \%$ \\
Pioglitazone & $15 \mathrm{mg} / \mathrm{tab}$ & $15.03 \mathrm{mg} / \mathrm{tab}$ & $100.2 \%$ \\
Metformin & $500 \mathrm{mgltab}$ & $497.33 \mathrm{mg} / \mathrm{tab}$ & $99.46 \%$ \\
\hline Zoryl MP2 & & & \\
Glimepiride & $2 \mathrm{mg} / \mathrm{tab}$ & $2.01 \mathrm{mg} / \mathrm{tab}$ & $100.5 \%$ \\
Pioglitazone & $15 \mathrm{mg} / \mathrm{tab}$ & $15 \mathrm{mg} / \mathrm{tab}$ & $100 \%$ \\
Metformin & $500 \mathrm{mgltab}$ & $501.02 \mathrm{mg} / \mathrm{tab}$ & $100.2 \%$ \\
\hline
\end{tabular}

3.7. Ruggedness. Data acquired and compared, \% RSD of area and RT has been calculated and tabulated in Table 6. Based on the data, it is evident that the method is Rugged.

3.8. Performance of the Drug/Batch Analysis. Two market samples have been analysed to see the performance of the method. First tablet taken was Triblend 1 which contains $1 \mathrm{mg}$ of glimepiride, $15 \mathrm{mg}$ of pioglitazone, and $500 \mathrm{mg}$ of metformin hydrochloride; the second tablet ZorylMP2 contains contains $2 \mathrm{mg}$ of glimepiride, $15 \mathrm{mg}$ of pioglitazone, and $500 \mathrm{mg}$ of metformin hydrochloride. Results obtained have been summarized in the Table 7 .

\section{Conclusion}

It is concluded from the above study that the current method is fast, reproducible, and simple. By adopting this method one can elute all the three drugs in 5 minutes. Hence this method is definitely time saving to enable the simultaneous estimation of glimepiride, pioglitazone, and metformin. The proposed method is found to be accurate, precise, linear, robust, and rugged.

\section{References}

[1] M. Dorkhan and A. Frid, "A review of pioglitazone HCL and glimepiride in the treatment of type 2 diabetes," Vascular Health and Risk Management, vol. 3, no. 5, pp. 721-731, 2007.

[2] A. Ramachandran, C. Snehalatha, J. Salini, and V. Vijay, "Use of glimepiride and insulin sensitizers in the treatment of type 2 diabetes-a study in Indians," Journal of Association of Physicians of India, vol. 52, pp. 459-463, 2004.

[3] D. Adukondalu, P. S. Malathy, J. V. Rao, and Y. M. Rao, "Development and validation of HPLC method for detection of pioglitazone hydrochloride in dosage forms," International Journal of Pharmacy and Biological Sciences, vol. 1, no. 4, pp. 474-478, 2011.

[4] D. B. Pathare, A. S. Jadhav, and M. S. Shingare, "RP-LC determination of the cis-isomer of glimepiride in a bulk drug substance," Chromatographia, vol. 66, no. 7-8, pp. 639-641, 2007.

[5] K. Mishra, H. Soni, G. Nayak, S. S. Patel, and A. K. Singhai, "Method development and validation of metformin hydrochloride in tablet dosage form," E-Journal of Chemistry, vol. 8, no. 3, pp. 1309-1313, 2011.

[6] A. Madhukar, A. Prince, R. Vijay Kumar, Y. Sanjeeva, K. Jagadeeshwar, and D. Raghupratap, "Simple and sensitive analytical method development and validation of metformin hydrochloride by RP-HPLC," International Journal of Pharmacy and Pharmaceutical Sciences, vol. 3, no. 3, pp. 117-120, 2011.

[7] M. Kar and P. K. Choudhury, "HPLC method for estimation of metformin hydrochloride in formulated microspheres and tablet dosage form," Indian Journal of Pharmaceutical Sciences, vol. 71, no. 3, pp. 318-320, 2009.

[8] A. Goyal and I. Singhvi, "Simultaneous spectrophotometric estimation of rosiglitazone maleate and glimepiride in tablet dosage forms," Indian Journal of Pharmaceutical Sciences, vol. 69, no. 6, pp. 780-783, 2007.

[9] K. Karthrik, G. Subramanian, C. Mallikarjuna Rao et al., "Simultaneous determination of pioglitazone and glimepiride in bulk drug and pharmaceutical dosage form by RP-HPLC method.", Pakistan Journal of Pharmaceutical Sciences, vol. 21, no. 4, pp. 421-425, 2008.

[10] P. C. Bhamare Dr., S. B. Bari Dr., S. Natarajan, A. A. Patil, and P. T. Shirode, "A new analytical method development 
and validation of metformin hydrochloride and fenofibrate by absorbance ratio UV spectrophotometric method," Asian Journal of Biochemical and Pharmaceutical Research, vol. 1, no. 2, pp. 2231-2560, 2011.

[11] P. C. Bhamare, S. B. Bari, S. Natarajan, A. A. Patil, S. H. Patil, and P. T. Shirode, "Development and validation of a precise single stability indicating HPLC method for determinations of Metformin hydrochloride and Fenofibrate, in pure form and in pharmaceutical tablets," International Journal of PharmTech Research, vol. 3, no. 1, pp. 505-515, 2011.

[12] R. T. Sane, S. N. Menon, S. Inamdar, M. Mote, and G. Gundi, "Simultaneous determination of pioglitazone and glimepiride by high-performance liquid chromatography," Chromatographia, vol. 59, no. 7-8, pp. 451-453, 2004.

[13] S. H. R. R. Munjewar and M. Faroui, "Simultaneous determination of atenolol and metformin hydrochloride by reverse phase high performance liquid chromatography,' Current Pharma Research, vol. 1, no. 1, pp. 44-48, 2010.

[14] S. P. Pawar, G. A. Meshram, and M. U. Phadke, "Simultaneous LC estimation of glimepiride and metformin in glimepiride immediate release and metformin sustained release tablets," Chromatographia, vol. 68, no. 11-12, pp. 1063-1066, 2008.

[15] F. H. Havaldar and D. L. Vairal, "Simultaneous estimation of metformin hydrochloride, rosiglitazone and pioglitazone hydrochloride in the tablet dosage form," International Journal of Applied Biology and Pharmaceutical Technology, vol. 1, no. 3, pp. 1000-1005, 2011.

[16] S. Havele and S. Dhaneshwar, "Development and validation of a HPLC method for the determination of Metformin Hydrochloride, Gliclazide and Pioglitazone Hydrochloride in multicomponent formulation," Webmed Central Pharmaceutical Sciences, vol. 1, no. 10, Article ID WMC0001078, 2010.

[17] S. K. Shetty, K. V. Surendranath, P. Radhakrishnanand et al., "Stress degradation behaviour of aspirin, atorvastatin, ramipril and metoprolol succinate," American Journal of Analytical Chemistry. In press.

[18] S. K. Shetty, K. V. Surendranath, P. Radhakrishnanand et al., "Quantitative application to a polypill by the development of stability indicating LC method for the simultaneous estimation of aspirin, atorvastatin, atenolol and losarton potassium," American Journal of Analytical Chemistry, vol. 2, no. 1, pp. 59-69, 2010.

[19] K. S. Lakshmi, T. Rajesh, S. Sharma, and S. Lakshmi, "Development and validation of Liquid chromatographic and UV derivative spectrophotometric methods for the determination of metformin, pioglitazone and glimepiride in pharmaceutical formulations," Der Pharma Chemica, vol. 1, no. 1, pp. 238-246, 2009.

[20] S. K. Shetty, K. V. Surendranath, J. Satish, J. Jogul, and U. M. Tripathi, "Determination of Zaleplon in the presence of its degradation products by a stability indicating UPLC method," Analytical Chemistry, vol. 8, no. 3, pp. 360-367, 2009.

[21] S. Shetty, K. Surendranath, R. Kaja, J. Satish, J. Jogul, and U. Manitripathi, "Development and validation of a stabilityindicating UHPLC method for assay of felbamate and related substances," Acta Chromatographica, vol. 22, no. 2, pp. 161-172, 2010 . 

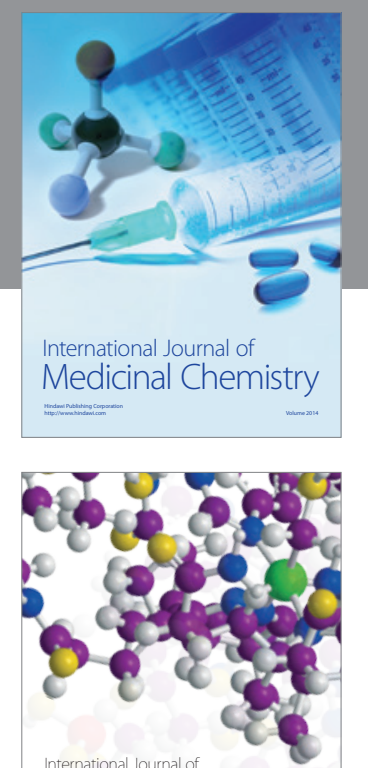

\section{Carbohydrate} Chemistry

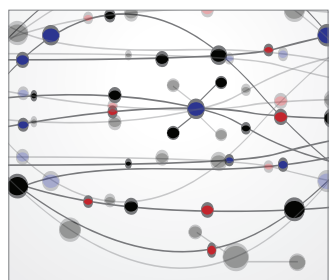

The Scientific World Journal
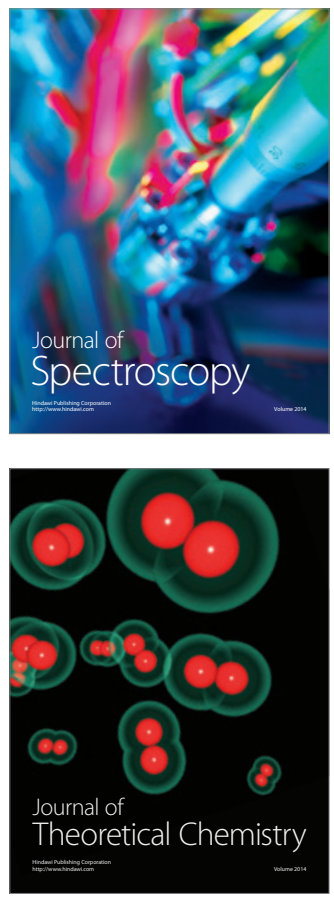
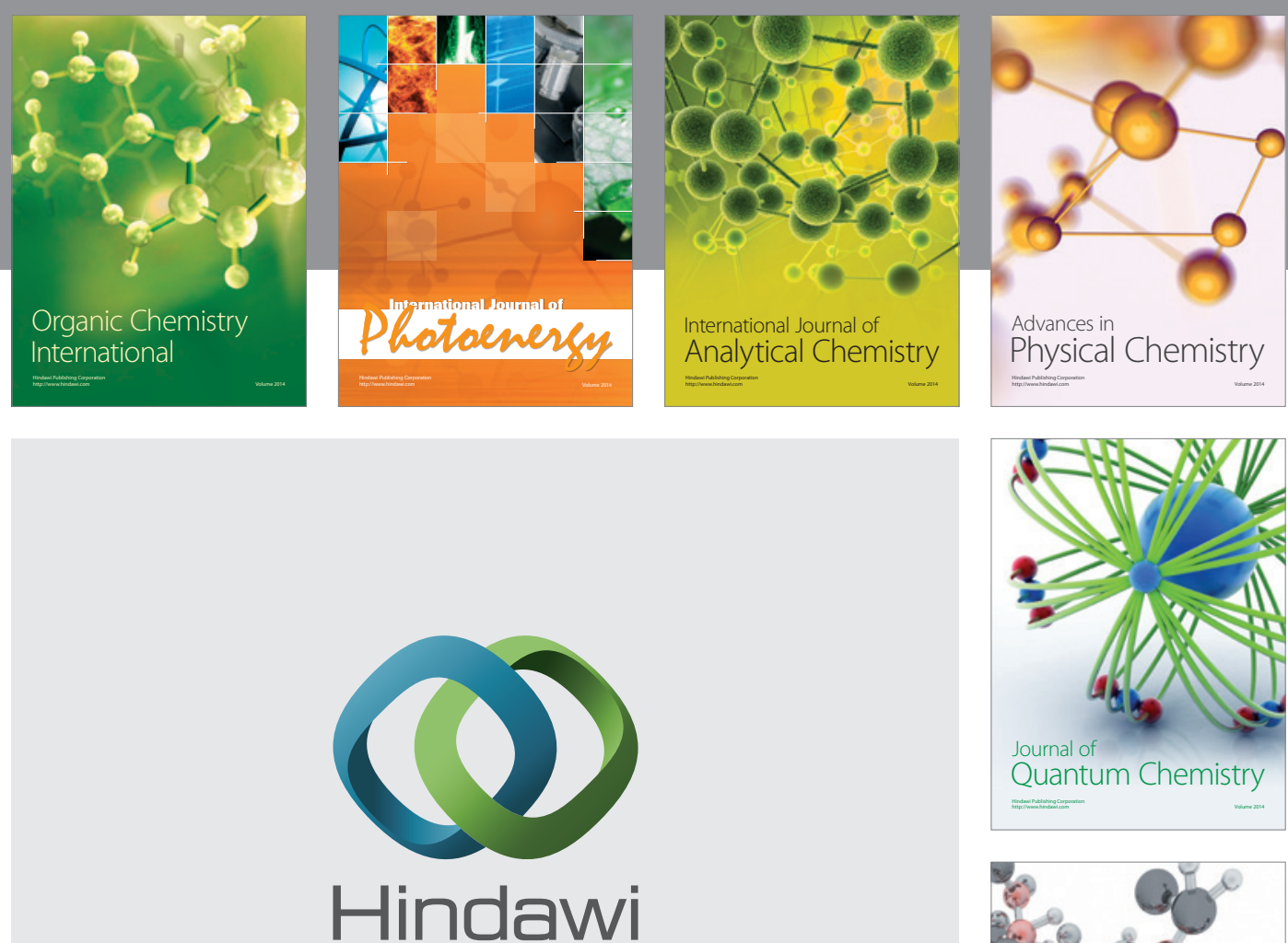

Submit your manuscripts at

http://www.hindawi.com

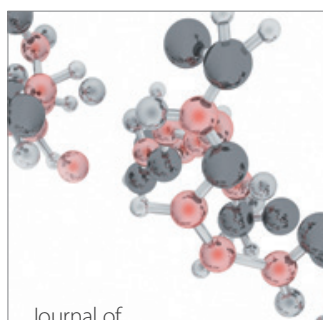

Analytical Methods

in Chemistry

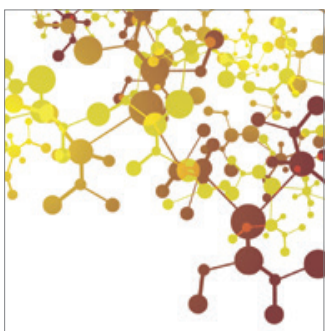

Journal of

Applied Chemistry

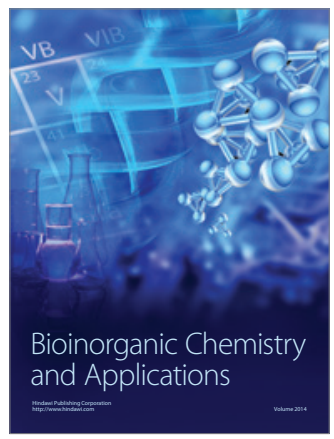

Inorganic Chemistry
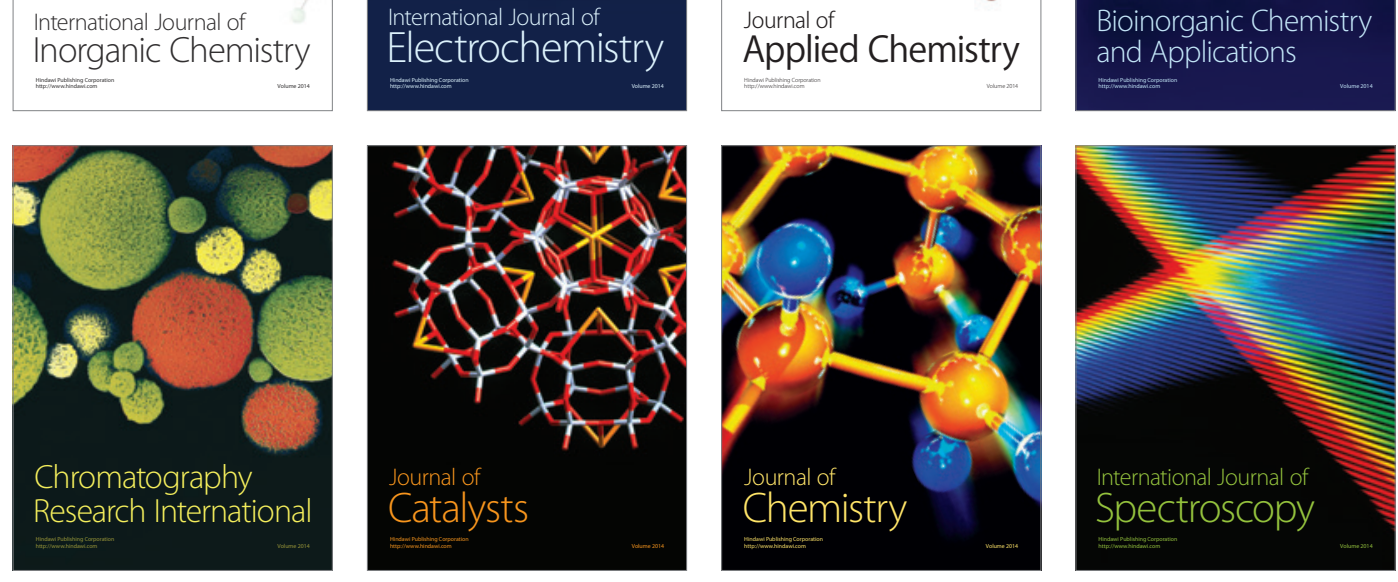